\title{
Importance-performance analysis of UK and US bank customer perceptions of service delivery technologies
}

\author{
Mathew Joseph* \\ Mitchell College of Business, University of South Alabama, \\ Mobile, Alabama 36688, USA \\ Fax: (251) 460-7909 E-mail: mjoseph@jaguar1.usouthal.edu \\ *Corresponding author
}

\section{David Allbright}

Department of Marketing, 469 Gary Owens Building, 300 West Michigan Avenue, Eastern Michigan University, Ypsilanti, MI 48197, USA

Fax: (734) 487-2378 E-mail: lexiallbright@aol.com

\section{George Stone}

McNeese State University, 4205 Ryan Street, Lake Charles, LA 70609, USA E-mail: gstone@mcneese.edu

\section{Yasmin Sekhon}

School of Business, Bournemouth University, Fern Barrow, Poole, Dorset, BH12 5BB, UK

E-mail: ysekhon@bournemouth.ac.uk

\section{Julie Tinson}

Department of Marketing, University of Stirling, Stirling,

FK9 4LA, Scotland, UK

E-mail: j.s.tinson@stir.ac.uk

\begin{abstract}
Importance-performance analysis is utilised to compare the perceptions held by bank customers regarding selected service delivery technologies (SDTs) such as automated teller machines (ATMs), telephone banking and internet banking. Bank patrons in the United Kingdom and the United States are surveyed to examine which service delivery factors they consider to be most important toward assessing the performance of SDTs offered by banking institutions. Customer views are plotted onto importance-performance grids which offer banking strategists a straightforward, graphic illustration of service factors that patrons consider to be salient and well-addressed by current installations of bank SDTs in each respective nation. The grids also offer heuristic decision guides for translating customer perceptions into strategic allocations of organisational investments toward SDTs.
\end{abstract}


Keywords: banking service; cross cultural comparison; customer perception; customer service; importance performance analysis; resource allocation; service delivery technologies; service performance; service quality; service strategy.

Reference to this paper should be made as follows: Joseph, M., Allbright, D., Stone, G., Sekhon, Y. and Tinson, J. (2005) 'Importance-performance analysis of UK and US bank customer perceptions of service delivery technologies', Int. J. Finance Services Management, Vol. 1, No. 1, pp.66-88.

Biographical notes: Dr Mathew Joseph is a professor of Marketing at University of South Alabama, Mobile, Alabama, USA. He holds an MBA from Southeast Missouri State University and a $\mathrm{PhD}$ from the University of Waikato in New Zealand. He has taught at universities in the USA, New Zealand, Australia and Portugal. He is the author of a number of articles in the areas of cross cultural marketing, service quality, marketing strategy, healthcare marketing, electronic marketing, service technology, international advertising and promotion, marketing to Asia and Latin America and marketing education.

Dr David Allbright (PhD in Marketing, 2000, University of Georgia, Athens, GA) has served as an assistant professor of Marketing and Sales at Eastern Michigan University in Ypsilanti, MI, at Augusta State University in Augusta, GA, and also at Georgia College in Milledgeville, GA. His present research centres on market-orientated learning and sensemaking processes within corporate strategy dialogues. Dr Allbright has also provided ten years' service as an architect of corporate marketing information systems and new media publishing systems for NASA, XEROX, Ford Motor Company, Comerica Bank and SBC Ameritech.

George W. Stone is an associate professor of Marketing at McNeese State University in Lake Charles, Louisiana. He received his undergraduate degree in 1978 from the United States Military Academy and served eight years in the US Military, to include four years serving in Europe. In addition to a BS, Dr Stone holds an MBA from Boston University and received his $\mathrm{PhD}$ in Marketing in 1995 from the University of Mississippi. He has taught at universities in Nicaragua, Kentucky, Ohio, and prior to his current assignment, was a tenured marketing professor at Georgia College \& State University in Milledgeville, Georgia.

Yasmin K. Sekhon is a senior lecturer at Bournemouth University (UK). She is an active researcher and has published in a number of fields. Her subject specialisms include financial marketing, cross cultural marketing and consumption research. In particular she enjoys researching cross cultural projects from a number of perspectives, customer service, different industries across countries and consumer behaviour patterns, especially those from ethnic minorities. She has been publishing and lecturing for over seven years and has publications at both national and international level. Yasmin is currently working with a number of colleagues and researchers both in the UK and the USA.

Dr Julie Tinson has recently been appointed as a lecturer in Marketing at Stirling University in Scotland. Her research interests principally lie in family decision making although she has also published in the areas of consumer behaviour, health services marketing and branding. Her teaching specialism is marketing communications. This is facilitated by a wide number of funded research projects including work for Barclays Bank and, more recently, Channel 4 television. 


\section{Introduction}

Customer service is a key strategic component toward enhancing corporate image, market share and profitability. Service delivery processes that satisfy customer desires or exceed service expectations can help create and maintain long-term relationships with loyal customers (Rust and Zahorik, 1993). In an effort to provide additional service delivery options to their current and prospective customers, many banking institutions have made extensive capital investments in service delivery technologies (SDTs) such as automated teller machines (ATMs), automated menu-driven telephone answering services and internet banking. As a result, banking SDTs have become ubiquitous in many countries.

Since competitive positioning now involves the implementation of various SDTs within each bank's service delivery mix, banking strategists are increasingly faced with difficult choices regarding the allocation of scarce organisational resources toward current and emerging service delivery technologies. A market-orientated firm (Kohli and Jaworski, 1990; Narver and Slater, 1990) would seek to create and nurture long-term customer relationships by identifying, understanding and satisfying customer desires in a way that would also be profitable for the firm (Slater and Narver, 2000). So, organisations focused on meeting or exceeding customer desires for selected services would endeavour to identify the service delivery technology features that customers consider most important. Similarly, customer evaluations of the performance of selected bank SDTs would inform decisions to construct, upgrade or de-emphasise each service technology offering.

Academic researchers (Hawes and Rao, 1985; Hermmasi et al., 1994; Martilla and James, 1977; Swinyard 1980) advocate the use of importance-performance analysis (IPA) as a managerially relevant approach toward translating customer perceptions of service into strategic deployments of organisational attentions and resources. There is a precedent for using IPA to gain a better understanding of banking customer perceptions of selected service factors (Ennew et al., 1993; Joseph et al., 1999; Joseph and Stone, 2003; Swinyard, 1980). Others have used IPA to study customer perceptions of service quality in healthcare (Hawes and Rao, 1985) and to interpret student evaluations of educational services (Ford et al., 1999; Ortinau et al., 1989). Leading banking practitioners (Albro, 1999; Motley, 1999) have advocated widespread adoption of the importance-performance grid (described in detail later in this article) as a useful heuristic decision tool to guide strategic analysis (e.g. the American Banking Association's Financial Client Satisfaction Index at www.clientsatisfaction.com).

Previous IPA research regarding banking customers' perceptions of bank service delivery technologies have focused on single-country studies including the United States (Joseph and Stone, 2003), Australia (Joseph et al., 1999) and the United Kingdom (Ennew et al., 1993). While the aforementioned studies have provided useful insights regarding customer perceptions within a single nation, these inquiries do not explicitly compare bank customer perceptions across two or more nations. One recent cross-country study (Pyun et al., 2002) focused primarily on internet banking services rather than on capturing customer evaluations of the broader spectrum of technology-based service delivery systems.

This article begins to address the gap in the literature by conducting an importance-performance analysis of customer perceptions regarding bank service delivery technologies within two countries: the United Kingdom (UK) and the United States (US). The inquiry centres on descriptive endeavours rather than on theory testing. 
The study also focuses on summarising customer evaluations of a wider variety of bank service delivery technologies than was addressed by a previous cross-country study (Pyun et al., 2002).

Another contribution of this report is that several previous suggestions (Albro, 1999; Hawes and Rao, 1985; Hermmasi et al., 1994; Martilla and James, 1977; Swinyard, 1980) for implementing an IPA are integrated into a more comprehensive approach. Of particular relevance to banking strategists is a detailed explanation of how to construct and reflect upon an importance-performance grid (I-P grid) which is a straightforward, graphic illustration of service delivery factors that customers consider to be good enough, in need of more attention, or perhaps receiving too much organisational attention and resources. This article also extends the IPA methodology for use in a dual-country inquiry. I-P grids are presented in this article to provide graphic illustrations of UK and US customer perceptions of banking SDTs within each country.

The importance-performance analysis methodology is detailed later, along with findings, conclusions, implications for practitioners and implications for future academic research. Firstly, the following section examines relevant literature that discusses the strategic impact of creating, implementing and updating various banking SDTs.

\section{Strategic perceptions of banking service delivery technologies}

Many banks originally implemented service delivery technologies as a way of reducing internal costs. For example, ATMs and automated, menu-driven telephone answering services could absorb some demand for services provided traditionally by bank personnel. Besides reducing personnel costs, banks could also reduce transaction costs by realising an increase in speed, efficiency and consistency by which their internal operations processes would handle a multitude of repetitive financial transactions (Alstad, 2002; Byers and Lederer, 2001).

Some bank customers may resist utilising banking SDTs because they may be unfamiliar with the technology, feel uncomfortable with using the SDT, mistrust the outcomes of using the service delivery process, or simply prefer having face-to-face contact with bank personnel. On the other hand, there is a growing segment of bank customers that prefer to utilise self-service delivery systems to conduct at least of portion of their banking transactions (Pyun et al., 2002; Quinn, 1996). Many individuals feel empowered when they are given the option to forgo interacting with bank personnel to instead complete their banking transactions on their own through ATMs, telephone calls or the internet. These individuals are often willing to trade-off the flexible, real-time assistance of person-to-person contact with bank employees to instead enjoy the feeling of increased control and autonomy that they receive through the use of self-service delivery technologies (Bateson, 1985; Cowles and Crosby, 1990). In addition, some customers perceive interactions with technology-based service delivery processes to be faster and more efficient than similar interactions with service employees (Ledingham, 1984). Other benefits for customers that utilise SDTs include the increased convenience of having 24-hour-a-day, seven-days-a-week access to selected financial services from a multitude of access locations - including from their own home telephone or computer.

Since a growing segment of bank customers now perceive SDTs to provide multiple benefits including convenience, accessibility, autonomy and control, banking strategists 
may consider making investments in SDTs as a way to attract and retain this segment of customers. Increased investments in SDTs may allow banks to reap the benefits of increased customer loyalty and service satisfaction in addition to the original benefits of reduced internal costs and increased operational efficiencies.

However, SDTs are not a panacea. Banking strategists must remember that there is a continuum of customer preferences for service delivery contact processes. For example, customers may desire various 'who/what' combinations (Dabholkar, 1994) of service delivery contact processes including customer-to-employee, customer-to-technology, customer-to-employee with assistance from technology, or customer-to-technology with assistance from employee. In addition, there is a continuum of customer choices regarding the location for consummating service transactions including the bank's branch office, the customer's home, or various 'neutral locations' (Dabholkar, 1994) such as wireless internet access areas or ATMs in airports and grocery stores.

Customers may also differ as to the degree of importance they place upon various service quality evaluation criteria such as the speed and efficiency in consummating a service transaction, accuracy of the outcome of a transaction, feelings of autonomy and self-control during a transaction, widespread accessibility to a service, ease of understanding of how to use a service, amount of time spent waiting in a service delivery queue, feelings of personal comfort and safety, availability of employees to handle complaints, confidence in the bank, personalised greetings from technologies/employees and aesthetic surroundings (Joseph and Stone, 2003).

The preceding survey of literature which describes and theorises about customer perceptions and preferences for SDTs suggests that bank strategists must sift through a daunting cornucopia of service factors during attempts to prioritise SDT resource allocations. Informed strategic decisions would be greatly assisted by addressing the following questions: Which aspects of SDTs do bank customers perceive to be most valuable or important? Are bank patrons currently satisfied with the SDTs that are offered? Which aspects of current SDTs warrant increased organisational emphasis and attention? Which service elements do customers consider to be 'good enough?' Which service factors are not considered important enough by customers to warrant additional organisational attention and resources? Do banking customer perceptions of service delivery technologies differ across countries? The following section describes how the IPA methodology can be used toward addressing the preceding questions.

\section{Methodology: importance-performance analysis}

A survey of approaches toward conceiving and implementing an importance-performance analysis (Albro, 1999; Hawes and Rao, 1985; Hermmasiet al., 1994; Martilla and James, 1977; Swinyard, 1980) indicates that IPA essentially involves the following steps. Firstly, utilise focus groups or experts to create a list of salient attributes for selected service delivery technology offerings. Next, devise a survey instrument to determine the relative level of importance that patrons assign to each service delivery factor and also to obtain customer evaluations regarding the actual performance of each service factor. Finally, plot aggregate customer viewpoints on an importance-performance grid (I-P grid) that can promote strategic analysis which informs the allocation of scarce organizational resources (Martilla and James, 1977). 
A more detailed description of the focus groups and the survey instruments used to ascertain the respective perceptions of US and UK bank patrons will be presented later in this article in the section titled 'Data Collection'. The remainder of the present section provides an in-depth explanation of how to create and analyse an importance-performance grid (Martilla and James, 1977).

Figure 1 presents a generic example of an importance-performance grid (I-P grid). The vertical y-axis represents the 'level of importance' and the horizontal $\mathrm{x}$-axis represents the 'level of performance' that bank patrons perceive regarding selected service delivery factors. Martilla and James (1977) suggest that organisational decision makers can obtain useful conceptual insights by overlaying the importance-performance grid with the following four quadrants and labels:

- Quadrant A (Concentrate Here): service factors that customers consider to be relatively important - and are receiving relatively less than desired service performance.

- Quadrant B (Keep Up The Good Work): service factors that customers consider to be relatively important - and are receiving relatively desirable service performance.

- Quadrant C (Low Priority): service factors that customers consider to be relatively less important - and are receiving either adequate or less than desired service performance.

- Quadrant D (Possible Overkill): service factors that customers perceive as relatively less important - and are receiving better than required performance.

Figure 1 Interpreting the importance-performance grid

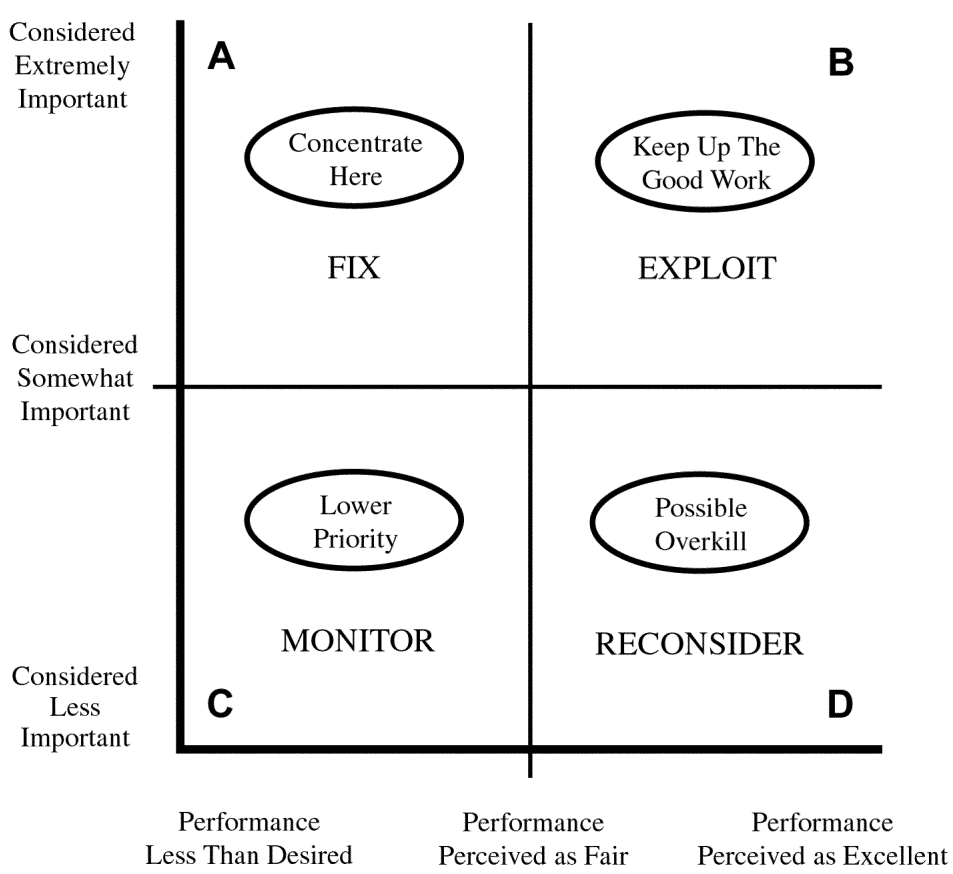

Source: Adapted from Martilla and James, 1977; Albro, 1999. 
Some bank industry leaders (Albro, 1999; Motley, 1999) agree that the importance-performance grid offers strategic insights for organisational decision makers faced with difficult choices regarding the allocation of scarce organisational resources toward various service offerings. The following is a short summary of how organisational analysts may translate the customer perceptions that are plotted on an I-P grid into suggestions for strategic actions.

- Quadrant A (Fix): Allocate additional resources toward service delivery technologies that may satisfy customers who feel under-served on relatively important matters.

- Quadrant B (Exploit): Continue to allocate organisational resources toward maintaining exemplary service within these relatively important service factors. In addition, consider exploiting current strategic strengths by creating advertisements that emphasise their high performance service technologies that are valued by target segments.

- Quadrant C (Monitor): Strategists may be hesitant to allocate scarce organisational resources toward service factors that customers consider to be less important. However, decision makers should remember that patrons may still demand a minimum level of service on relatively less important service factors.

- Quadrant D (Reconsider): Over-committed scarce organisational resources toward providing exemplary service delivery factors that customers consider to be relatively less important. Decision makers may wish to re-allocate resources elsewhere.

There are two common approaches (Hermmasi et al., 1994; Martilla and James, 1977) toward locating the placement of the cross-hairs that create the respective boundaries of the four quadrants of the importance-performance grid. Martilla and James (1977) advocate placing the $\mathrm{x}$ and $\mathrm{y}$ cross-hairs respectively at a grid value that corresponds to the mid-point of the original rating scales. For example, if a survey asks customers to rate the importance of each service factor on a scale of 1 to 6 , then the mid-point of the rating scale is 3.5. Therefore, 3.5 would be the grid location of the horizontal cross-hair that would serve to visually divide the vertical y-axis into two areas that indicate service factors which customers consider relatively more or less important. Hemmasi et al. (1994) suggest an alternative approach that locates the two cross-hairs respectively at the overall means of the importance ratings and performance ratings across the entire list of service factors from the entire pool of surveyed customers. Interestingly, Hemmasi offers no reasons for choosing to utilise overall means to determine the placement of the grid cross-hairs versus the alternative method of utilising the mid-points of the original ratings scale that was suggested by Martilla and James (1977).

Ultimately, the subjective choice of grid cross-hair placement depends on the analyst's preferences for presenting a cogent visualisation of customer perceptions. Choose the Martilla and James method in order to compare the perception ratings of various survey groups against a common base rating, or choose the Hemmasi approach to promote a relative comparison of what various groups consider to be an average rating of importance-performance. For the purposes of this study, we have chosen the Hemmasi method of locating the grid cross-hairs because it provides a relatively more flexible and comprehensible approach toward comparing the aggregate perceptions two independent sample groups of bank patrons from different countries. 


\section{Data collection}

The data for this study were collected in two stages. In stage one, customer focus groups were organised in the United States and Great Britain to obtain bank patrons' opinions regarding selected bank service delivery technologies including ATMs, telephone assistance and internet banking. Four focus groups were organised in each country. Each focus group was comprised of eight to 12 participants. One of the four groups contained younger bank patrons aged 18-24. A second group was comprised of mature customers over the age of 55 . The remaining focus groups contained individuals between the ages of 35-54.

The outcome of the focus group dialogues was the creation of a list of 23 attributes of service delivery technologies deemed relatively important by discussants (see Tables 1-4 for a detailed listing of salient service delivery attributes). While bank customers in each country differed somewhat in their evaluations of the relative importance of various service factors (see Table 4) the final list of 23 items included only those items considered relatively important by either country's focus customers. The list of 23 important service delivery elements inspired the development of a survey instrument utilised in the second stage of data collection.

Table 1 US bank customer perceptions

\begin{tabular}{|c|c|c|c|c|}
\hline \multicolumn{2}{|c|}{ Electronic bank service technologies overall } & Importance & Performance & $P-I$ \\
\hline \multicolumn{5}{|c|}{ An ideal electronic banking service should: } \\
\hline Q1: & Be easy to use & 4.73 & 4.55 & -0.18 \\
\hline Q2: & Have convenient hours of operation ( $24 \mathrm{hrs} /$ day, 7 days/wk) & 4.73 & 4.67 & -0.06 \\
\hline Q3: & Have all my banking needs included in the menu options & 4.58 & 4.52 & -0.06 \\
\hline Q4: & Process my transactions efficiently (so I don't need to wait) & 4.70 & 4.42 & -0.28 \\
\hline Q5: & Provide brochures to new users to explain how to use services & 4.42 & 4.06 & -0.36 \\
\hline Q6: & Be able to set up accounts to perform transactions immediately & 4.40 & 4.20 & -0.20 \\
\hline Q7: & Be capable of performing all transactions accurately & 4.79 & 4.59 & -0.20 \\
\hline Q8: & Give you a written guarantee that transactions have taken place & 4.77 & 4.63 & -0.14 \\
\hline Q9: & Provide accurate records of all transactions that have taken place & 4.80 & 4.70 & -0.10 \\
\hline Q10: & Be personalised, (i.e. 'Greet me by using my name') & 3.41 & 3.56 & +0.15 \\
\hline Q11: & Provide special services for the elderly /disabled (electronic) & 4.32 & 4.16 & -0.16 \\
\hline Q12: & Be able to adequately satisfy my complaints within 24 hours & 4.38 & 4.25 & -0.13 \\
\hline Q13: & Provide customer feedback services & 4.32 & 4.09 & -0.23 \\
\hline \multicolumn{5}{|c|}{$\begin{array}{l}\text { ATMs } \\
\text { An ideal electronic banking service should: }\end{array}$} \\
\hline Q14: & Have its ATMs conveniently located & 4.77 & 4.47 & -0.30 \\
\hline Q15: & Provide secure services, (well lit, safe, night time ATM banking) & 4.79 & 4.74 & -0.05 \\
\hline Q16: & Provide special ATM services for the disabled & 4.47 & 4.26 & -0.21 \\
\hline Q17: & Acknowledge me by name on the screen during transaction & 3.83 & 3.83 & 0.00 \\
\hline Q18: & Have a user-friendly system to make ATM transactions easier & 4.58 & 4.23 & -0.35 \\
\hline
\end{tabular}


Table 1 US bank customer perceptions (continued)

\begin{tabular}{|c|c|c|c|c|}
\hline \multicolumn{2}{|c|}{ Electronic bank service technologies overall } & Importance & Performance & $P-I$ \\
\hline \multicolumn{5}{|c|}{$\begin{array}{l}\text { Telephone banking and/or internet banking } \\
\text { An ideal electronic banking service should: }\end{array}$} \\
\hline Q19: & Connect me immediately to the service, with no waiting time & 4.37 & 4.24 & -0.13 \\
\hline Q20: & Provide 'voice/on line' directions for new users & 4.17 & 4.16 & -0.01 \\
\hline Q21: & $\begin{array}{l}\text { Provide special communications options (e.g. for sight impaired, } \\
\text { hearing impaired, elderly, or non-English speaking customers) }\end{array}$ & 4.34 & 4.14 & -0.20 \\
\hline Q22: & $\begin{array}{l}\text { Provide customer-friendly environment whilst waiting in the } \\
\text { queue (e.g. provide music) }\end{array}$ & 3.68 & 3.72 & +0.04 \\
\hline Q23: & $\begin{array}{l}\text { Provide customer-friendly environment whilst waiting in the } \\
\text { queue (e.g. present information about services the bank provides) }\end{array}$ & 3.39 & 3.53 & +0.14 \\
\hline
\end{tabular}

Table 2 UK bank customer perceptions

\begin{tabular}{|c|c|c|c|c|}
\hline \multicolumn{2}{|c|}{ Electronic bank service technologies overall } & Importance & Performance & $P-I$ \\
\hline \multicolumn{5}{|c|}{ An ideal electronic banking service should: } \\
\hline Q1: & Be easy to use & 4.47 & 4.03 & -0.44 \\
\hline Q2: & Have convenient hours of operation ( $24 \mathrm{hrs} /$ day, 7 days/wk) & 4.46 & 4.18 & -0.28 \\
\hline Q3: & Have all my banking needs included in the menu options & 4.27 & 3.86 & -0.41 \\
\hline Q4: & Process my transactions efficiently (so I don't need to wait) & 4.46 & 3.96 & -0.50 \\
\hline Q5: & Provide brochures to new users to explain how to use services & 4.03 & 3.54 & -0.49 \\
\hline Q6: & Be able to set up accounts to perform transactions immediately & 4.27 & 3.80 & -0.47 \\
\hline Q7: & Be capable of performing all transactions accurately & 4.49 & 4.07 & -0.42 \\
\hline Q8: & Give you a written guarantee that transactions have taken place & 4.31 & 4.01 & -0.30 \\
\hline Q9: & Provide accurate records of all transactions that have taken place & 4.68 & 4.01 & -0.67 \\
\hline Q10: & Be personalised, (i.e. 'Greet me by using my name') & 3.46 & 3.06 & -0.40 \\
\hline Q11: & Provide special services for the elderly /disabled (electronic) & 3.94 & 3.43 & -0.51 \\
\hline Q12: & Be able to adequately satisfy my complaints within 24 hours & 4.24 & 3.67 & -0.57 \\
\hline Q13: & Provide customer feedback services & 4.12 & 3.73 & -0.39 \\
\hline \multicolumn{5}{|c|}{$\begin{array}{l}\text { ATMs } \\
\text { An ideal electronic banking service should: }\end{array}$} \\
\hline Q14: & Have its ATMs conveniently located & 4.33 & 3.98 & -0.35 \\
\hline Q15: & Provide secure services, (well lit, safe, night time ATM banking) & 4.35 & 3.78 & -0.57 \\
\hline Q16: & Provide special ATM services for the disabled & 3.98 & 3.35 & -0.63 \\
\hline Q17: & Acknowledge me by name on the screen during transaction & 3.33 & 2.90 & -0.43 \\
\hline Q18: & Have a user-friendly system to make ATM transactions easier & 4.12 & 3.74 & -0.38 \\
\hline \multicolumn{5}{|c|}{$\begin{array}{l}\text { Telephone banking and/or internet banking } \\
\text { An ideal electronic banking service should: }\end{array}$} \\
\hline Q19: & Connect me immediately to the service, with no waiting time & 4.27 & 3.52 & -0.75 \\
\hline Q20: & Provide 'voice/on line' directions for new users & 4.07 & 3.61 & -0.46 \\
\hline Q21: & $\begin{array}{l}\text { Provide special communications options (e.g. for sight impaired, } \\
\text { hearing impaired, elderly, or non-English speaking customers) }\end{array}$ & 4.07 & 3.39 & -0.68 \\
\hline Q22: & $\begin{array}{l}\text { Provide customer-friendly environment whilst waiting in the } \\
\text { queue (e.g. provide music) }\end{array}$ & 3.71 & 3.36 & -0.3 \\
\hline Q23: & $\begin{array}{l}\text { Provide customer-friendly environment whilst waiting in the } \\
\text { queue (e.g. present information about services the bank provides) }\end{array}$ & 3.13 & 3.32 & +0.19 \\
\hline
\end{tabular}


Table 3 Perceived performance of service: UK and US customers

\begin{tabular}{|c|c|c|}
\hline Electronic bank service technologies overall & $U K$ & US \\
\hline \multicolumn{3}{|l|}{ An ideal electronic banking service should: } \\
\hline Be easy to use & 4.03 & 4.55 \\
\hline Have convenient hours of operation ( $24 \mathrm{hrs} /$ day, 7 days/wk) & 4.18 & 4.67 \\
\hline Q3: Have all my banking needs included in the menu options & 3.86 & 4.52 \\
\hline Q4: Process my transactions efficiently (so I don't need to wait) & 3.96 & 4.42 \\
\hline Provide brochures to new users to explain how to use services & 3.54 & 4.06 \\
\hline Be able to set up accounts to perform transactions immediately & 3.80 & 4.20 \\
\hline Be capable of performing all transactions accurately & 4.07 & 4.59 \\
\hline Give you a written guarantee that transactions have taken place & 4.01 & 4.63 \\
\hline Q9: Provide accurate records of all transactions that have taken place & 4.01 & 4.70 \\
\hline Q10: Be personalised, (i.e. 'Greet me by using my name') & 3.06 & 3.56 \\
\hline Q11: Provide special services for the elderly /disabled (electronic) & 3.43 & 4.16 \\
\hline Q12: Be able to adequately satisfy my complaints within 24 hours & 3.67 & 4.25 \\
\hline Q13: Provide customer feedback services & 3.73 & 4.09 \\
\hline \multicolumn{3}{|l|}{$\begin{array}{l}\text { ATMs } \\
\text { An ideal electronic banking service should: }\end{array}$} \\
\hline Q14: Have its ATMs conveniently located & 3.98 & 4.47 \\
\hline Q15: Provide secure services, (well lit, safe, night time ATM banking) & 3.78 & 4.74 \\
\hline Q16: Provide special ATM services for the disabled & 3.35 & 4.26 \\
\hline Q17: Acknowledge me by name on the screen during transaction & 2.90 & 3.83 \\
\hline Q18: Have a user-friendly system to make ATM transactions easier & 3.74 & 4.23 \\
\hline \multicolumn{3}{|l|}{$\begin{array}{l}\text { Telephone banking and/or internet banking } \\
\text { An ideal electronic banking service should: }\end{array}$} \\
\hline Q19: Connect me immediately to the service, with no waiting time & 3.52 & 4.24 \\
\hline Q20: Provide 'voice/on line' directions for new users & 3.61 & 4.16 \\
\hline $\begin{array}{l}\text { Q21: Provide special communications options (e.g. for sight impaired, } \\
\text { hearing impaired, elderly, or non-English speaking customers) }\end{array}$ & 3.39 & 4.14 \\
\hline $\begin{array}{l}\text { Q22: Provide customer-friendly environment whilst waiting in the queue } \\
\text { (e.g. provide music) }\end{array}$ & 3.36 & 3.72 \\
\hline $\begin{array}{l}\text { Q23: Provide customer-friendly environment whilst waiting in the queue } \\
\text { (e.g. present information about services the bank provides) }\end{array}$ & 3.32 & 3.53 \\
\hline
\end{tabular}

Table 4 Perceived importance of service: UK and US customers

\begin{tabular}{lll}
\hline Electronic bank service technologies overall & UK & US \\
\hline An ideal electronic banking service should: & & \\
Q1: Be easy to use & 4.47 & 4.73 \\
Q2: Have convenient hours of operation (24 hrs/day, 7 days/wk) & 4.46 & 4.73 \\
Q3: Have all my banking needs included in the menu options & 4.27 & 4.58 \\
Q4: Process my transactions efficiently (so I don't need to wait) & 4.46 & 4.70 \\
Q5: Provide brochures to new users to explain how to use services & 4.03 & 4.42 \\
Q6: Be able to set up accounts to perform transactions immediately & 4.27 & 4.40 \\
Q7: Be capable of performing all transactions accurately & 4.49 & 4.79 \\
Q8: Give you a written guarantee that transactions have taken place & 4.31 & 4.77 \\
\hline
\end{tabular}


Table 4 Perceived importance of service: UK and US customers (continued)

\begin{tabular}{lll}
\hline Electronic bank service technologies overall & $U K$ & $U S$ \\
\hline An ideal electronic banking service should: & & \\
Q9: $\quad$ Provide accurate records of all transactions that have taken place & 4.68 & 4.80 \\
Q10: Be personalised, (i.e. 'Greet me by using my name') & 3.46 & 3.41 \\
Q11: Provide special services for the elderly /disabled (electronic) & 3.94 & 4.32 \\
Q12: Be able to adequately satisfy my complaints within 24 hours & 4.24 & 4.38 \\
Q13: Provide customer feedback services & 4.12 & 4.32 \\
ATMs & & \\
An ideal electronic banking service should: & 4.33 & 4.77 \\
Q14: Have its ATMs conveniently located & 4.35 & 4.79 \\
Q15: Provide secure services, (well lit, safe, night time ATM banking) & 3.98 & 4.47 \\
Q16: Provide special ATM services for the disabled & 3.33 \\
Q17: Acknowledge me by name on the screen during transaction & 4.12 \\
Q18: Have a user-friendly system to make ATM transactions easier & 4.58 \\
Telephone banking and/or internet banking & \\
An ideal electronic banking service should: & 4.27 \\
Q19: Connect me immediately to the service, with no waiting time & 4.37 \\
Q20: Provide 'voice/on line' directions for new users & 4.07 \\
Q21: Provide special communications options (e.g. for sight impaired, & 4.07 & 4.17 \\
Q22: Provide customer-friendly environment whilst waiting in the queue & 3.71 & 3.68 \\
Q23: Provide customer-friendly environment whilst waiting in the queue & 3.13 & 3.39 \\
$\quad$ (e.g. present information about services the bank provides) & & \\
\hline
\end{tabular}

Stage two of data collection involved administering paper questionnaires to banking patrons in the United States and the United Kingdom. Samples were obtained through shopping mall intercepts within the state of Georgia (US) and also within Bristol and Bournemouth (UK). The US survey was completed by 175 of 250 bank patrons for a $70 \%$ response rate. The UK sample obtained a $66 \%$ response rate with 198 surveys returned out of 300. The survey locations were selected purely for convenience, access and affordability. In order to facilitate cross-sample comparisons, the mall intercept subjects were drawn in quotas to ensure that the samples in each respective nation were similar in composition with regard to age, income, education and gender.

The questionnaire elicited evaluations from bank patrons regarding 23 attributes of service delivery technologies. Respondents completed Likert scales $(1=$ strongly disagree, $2=$ disagree, $3=$ neither agree or disagree, $4=$ agree, $5=$ strongly agree) which required subjects to express the relative level of importance they placed on each SDT attribute, as well as the actual performance of their bank on each SDT attribute. The questionnaire format followed the suggestion of Hemmasi et al. (1994) to employ distinct, separate measures of a subject's perceptions of importance versus the performance of each service attribute. For example, each survey respondent was first asked to offer their opinion regarding the importance of each service delivery attribute. Later, the subject would assess separately how well his/her bank actually performed on each service delivery factor. 


\section{Data analysis}

The raw data acquired from the aforementioned surveys were compiled into Tables 1-4 and Figures 2-5. The composition and analytical implications of each table and figure is now further explained. Table 1 shows the mean perceptions of US bank customers regarding the importance and performance of selected services. Table 2 lists the mean perceptions of UK customers on the same service delivery factors. Notice that each table contains three groupings of service factors. The first grouping addresses customers' general perceptions of all service delivery technologies. The middle grouping indicates patrons' opinions regarding ATMs. At the bottom third of the tables is a list of customer perceptions of telephone and internet banking services.

Figure 2 US customers - perceptions of service delivery technologies (overall)

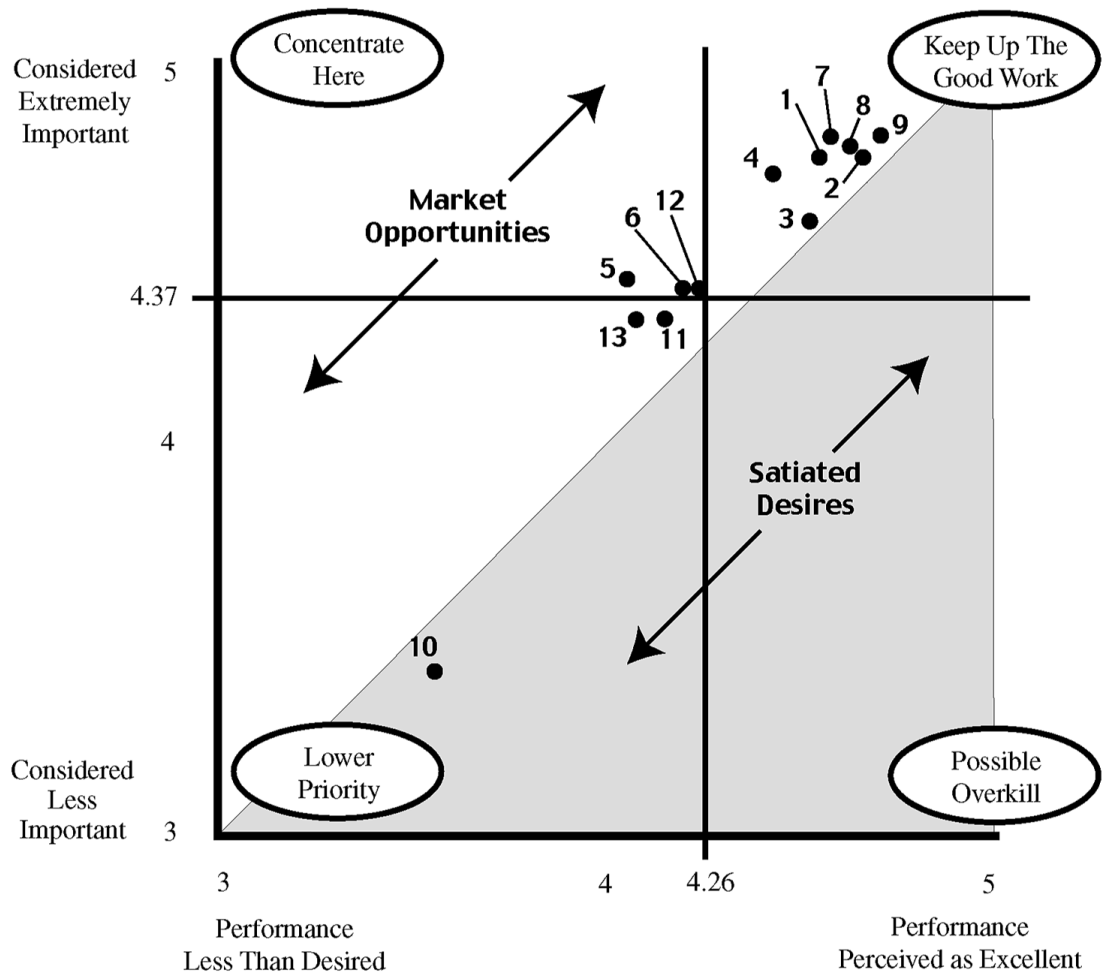

Source: Adapted from Martilla and James, 1977; Hawes and Rao, 1985. 
Figure 3 US customers - perceptions of ATM/telephone/internet banking services

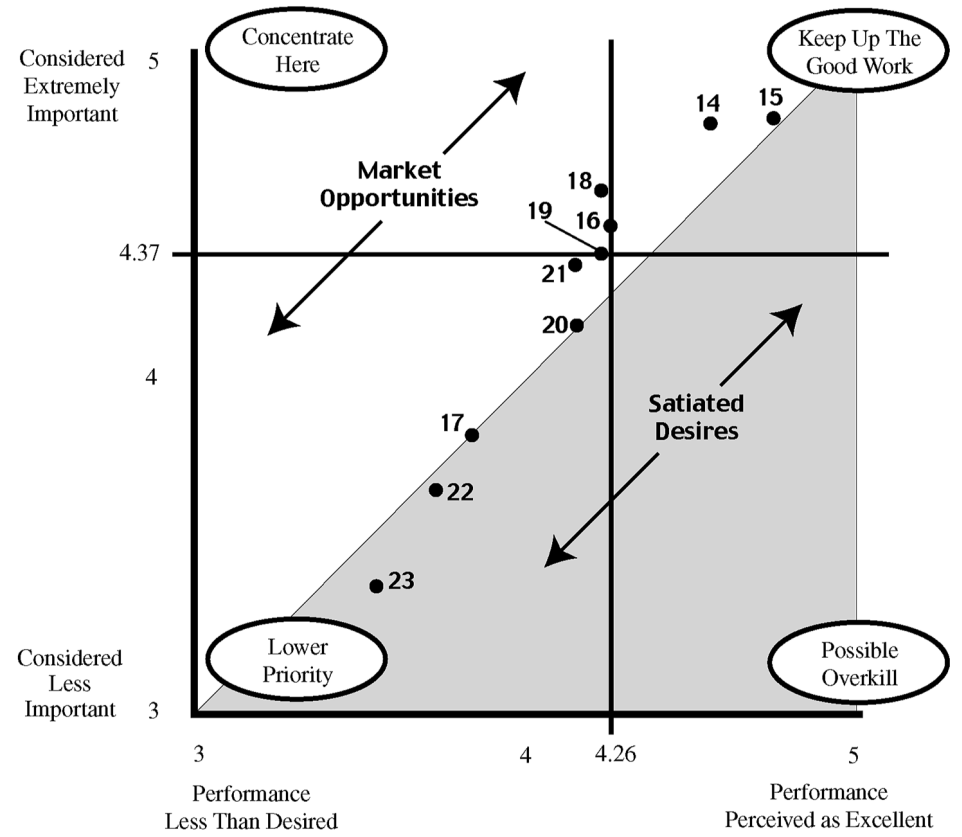

Source: Adapted from Martilla and James, 1977; Hawes and Rao, 1985.

Figure 4 UK customers - perceptions of service delivery technologies (overall)

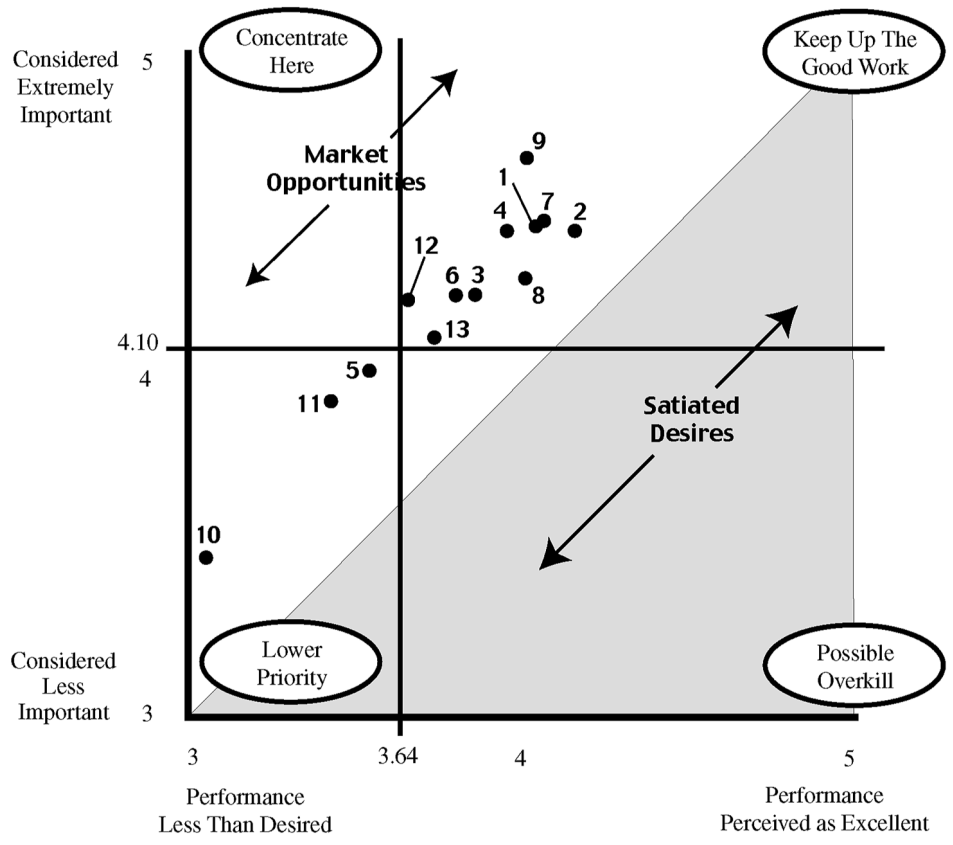

Source: Adapted from Martilla and James, 1977; Hawes and Rao, 1985. 
Figure 5 UK customers - perceptions of ATM/telephone/internet banking services

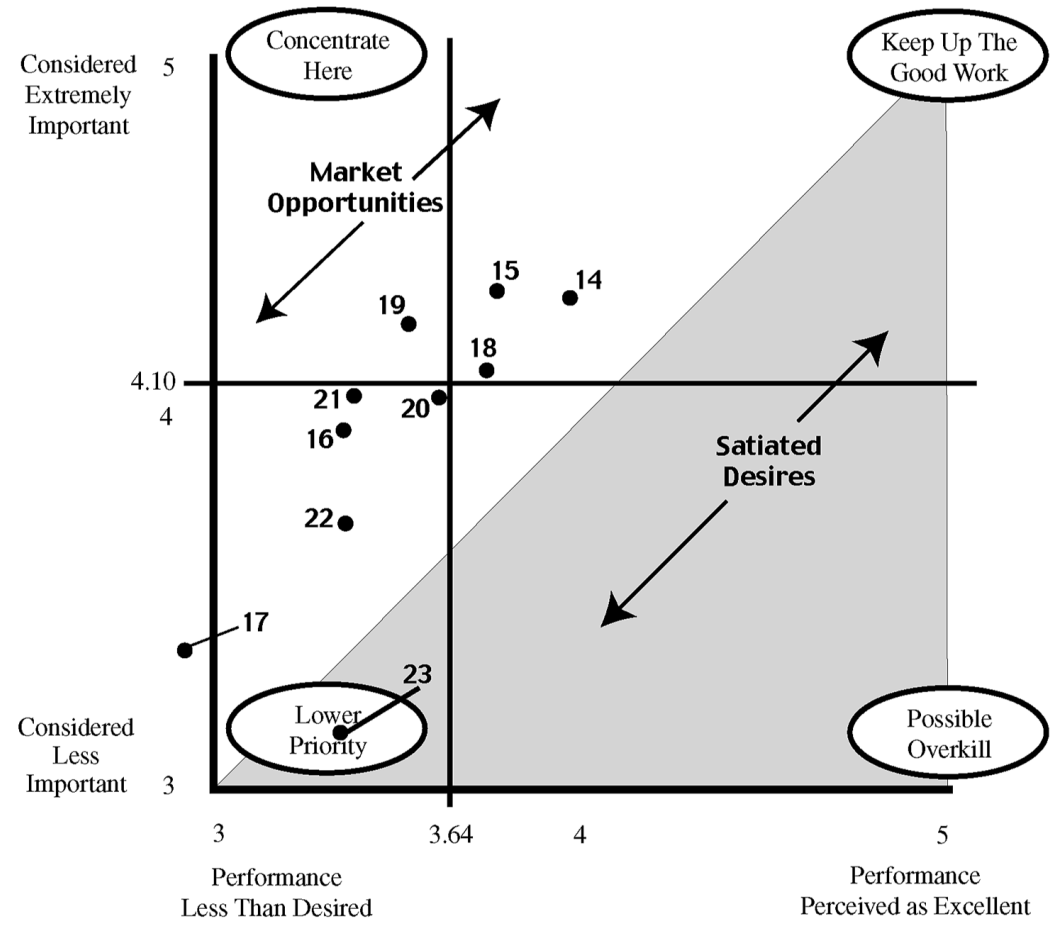

Source: Adapted from Martilla and James, 1977; Hawes and Rao, 1985.

The perceptions of US bank patrons listed in Table 1 are plotted within the importance-performance grids shown in Figures 2 and 3. Similarly, UK customer perceptions are listed in Table 2 and plotted in Figures 4 and 5. The location of the two cross-hairs which comprise the four quadrants of each IP grid (e.g. 4.26 on the $x$-axis and 4.37 on the y-axis in Figure 2) were determined by the overall composite mean of customer perceptions regarding all 23 service delivery attributes. Then, each individual service factor was plotted on the grid according to customers' mean perceived performance ( $\mathrm{x}$-axis value) and mean perceived importance (y-axis value). For example, the plot point in Figure 2 that is designated ' 1 ' corresponds with the first item listed in Table 1 (i.e. Q1: 'Be easy to use'). Points plotted on the grid to the left of the vertical cross-hair indicate service performance that customers considered 'below average'. Point plots to the right of the cross-hair denote an 'above average' performance evaluation. Similarly, service items plotted above the horizontal cross-hair represent services considered to possess above average importance.

Hawes and Rao (1985) suggest another visual amplification of the importance-performance grid. They recommend drawing a diagonal line through the grid to indicate all grid plot points where the mean perceived performance of a service attribute is equal to the perceived importance of the service. Notice in Figures 2-5 that an implied cross-diagonal line distinguishes the shaded 'satiated desires' versus the 
unshaded 'market opportunities' areas. The inclusion of the diagonal in the I-P grid provides organisational analysts with additional strategic insights because it offers a distinct visual cue that allows analysts to quickly compare the level of perceived service performance versus importance. For example, Figure 2 displays several service factors plotted in the upper, right-hand 'keep up the good work' quadrant. Organisational strategists might become somewhat complacent or hesitant regarding allocations of scarce company resources toward service factors located in the 'good work' category. However, the Hawes and Rao diagonal offers an additional visual stimulus that indicates that 'market opportunities' may be available to banks that would address customer desires for even greater performance on important service elements currently classified in the 'good work' category.

To further facilitate a direct comparison between perceived performance versus the perceived importance of each service factor, Tables 1 and 2 include a column entitled 'P-I'. A negative value in the P-I column indicates that the subject group's mean perception of bank performance is relatively lower than the mean perceived importance that the group places on the service to be performed. On the other hand, a positive P-I value indicates that the group feels the level of service performance is relatively greater than the importance of the service rendered.

Finally, Tables 3 and 4 compare the respective mean perceptions of US and UK customers regarding each of the 23 service delivery technology attributes. Table 3 compares how the two subject groups perceive bank service performance. Table 4 details which service attributes are considered important by the respective groups.

The following three sections present the findings of our inquiry. In addition, bank strategists are provided with detailed examples of how to construct, analyse and make strategic inferences from importance-performance grids. The first section outlines US bank customer perceptions regarding selected service delivery attributes. The second section offers the views of UK bank patrons regarding those same service items. The third section compares the respective opinions of US and UK bank patrons.

\section{US bank patron perceptions}

\subsection{Constructing importance-performance grids}

Table 1 summarises the aggregate views of sampled US bank patrons. Notice that the 'P-I' column in the table indicates that US customers tend to evaluate their bank's performance of services at a slightly lower level than the corresponding degree of importance they ascribe to each service. Only the following three service items - Q10 (be personalised - i.e., 'greet me by my name'), Q22 (provide customer-friendly environment whilst waiting in the queue - e.g., provide music), Q23 (provide customer-friendly environment whilst waiting in the queue - e.g., present information about services the bank provides) - appear to receive a customer evaluation of bank performance that is greater than the corresponding patron evaluation of the importance of the service. So, US banks appear to be quite adept at addressing customers by name and providing information and entertainment in the lobby waiting area. Unfortunately, the three aforementioned high-performance service items are considered by US customers to be relatively less important. Perhaps US customers care relatively less about personal courtesies and ambiance versus than other 
service attributes such as speed and accuracy. Additional strategic insights can be visualised by plotting the respective importance-performance means on an I-P grid. The first 13 service items in the table (Q1-Q13), which centre on general evaluations of all bank service delivery technologies, are placed on the grid shown in Figure 2. The final ten service items (Q14-Q23) which focus on customer perceptions of ATMs, telephone and internet services are plotted in Figure 3. The location of the cross-hairs that distinguish the quadrants of the grids shown in Figures 2 and 3 correspond to the aggregate mean evaluation of the entire sample of US customers regarding the performance (4.26) of their banks on all 23 service attributes as well as the importance (4.37) ascribed to all service items in total. So, service performance assessments above 4.26 are interpreted as 'above average' performance. Likewise, importance evaluations above 4.37 denote 'above average' importance.

\subsection{Overall evaluation of service delivery technologies}

We now focus on analysing customer perceptions of service delivery technologies overall that are plotted in Figure 2. Three service items fall into the upper, left-hand area of the grid referred to as 'concentrate here' which may be of concern to bank managers were items Q5 (provide brochures to new users to explain how to use services), Q6 (be able to set up accounts to perform transactions immediately), and Q12 (be able to adequately satisfy my complaints within 24 hours). These service delivery attributes may require some managerial attention because each is considered by customers to be relatively important, and yet, customers evaluate bank performance of these services to be slightly below average. Interestingly, these three items appear to address a key value of American consumers - time. For example, the information search focus of service item Q5 (provide brochures to new users to explain how to use services) perhaps addresses how US banking customers believe that the instructional brochure will easily address their questions without the need for personal assistance - and thus, may save them time. Since many US customers are already familiar with technology in a general sense, they may merely need a brochure to be informed on how to use the specific technological services offered by the bank of their choice. Hence, the findings here appear consistent with other US-based service research which indicates that time savings is one of the intrinsic values most highly regarded by American consumers.

The plots of service items Q1, Q2, Q3, Q4, Q7, Q8 and Q9 in the top-right quadrant of Figure 2 illustrates that many US customer assessments of overall service delivery technologies can be classified in the 'keep up the good work' category. This can be further interpreted as an indication that customers tend to rate the performance of US banks on the aforementioned seven important service items as 'above average' (i.e., above the aggregate mean performance rating of 4.26). However, bank managers are cautioned not be become complacent regarding the allocation of additional scarce organisational resources toward improving the delivery of these 'good work' services. For example, service items Q1 (be easy to use) and Q4 (process my transactions efficiently so that I don't have to wait) still have performance assessments that are relatively lower than the corresponding degree of perceived importance (i.e. are located in the un-shaded 'market opportunities' portion of the grid). So, there may be a strategic opportunity for ambitious banks to achieve competitive advantage by allocating additional organisational resources toward an exemplary delivery of services considered most important by customers. 
Three service delivery items are located in the lower, left-hand, 'lower priority' quadrant of Figure 2. The point-plot location of service items Q11 (provide specialised services for the elderly/disabled-electronic), and Q13 (provide customer feedback services) indicate that US customers consider the delivery of these services to be relatively acceptable for a service they consider to be of mid-range importance. However, item Q10 (be personalised - i.e. 'greet me by using my name') indicates that customers perceive banks to be performing very well on delivering this relatively unimportant service attribute.

\subsection{Perceptions of ATM/telephone/internet banking services}

Figure 3 plots service items that relate specifically to selected electronic banking services. Items Q14-Q18 represent five attributes of ATM services. Items Q19-Q23 are service attributes related to telephone and internet banking. The following items each fall into the 'lower priority' quadrant of Figure 3: item Q17 (acknowledge me by name on the screen during the transaction), item Q20 (provide 'voicelonline' directions for new users), item Q21 (provide special communications options - e.g. for sight impaired, hearing impaired, elderly, or non-English speaking customers), item Q22 (provide a customer-friendly environment whilst waiting in the queue - e.g. provide music), and item Q23 (provide a customer-friendly environment whilst waiting in the queue - e.g. present information about services the bank provides). Service items Q20 and Q21 appear to be valued more highly than the other items falling in the low priority quadrant and also appear to fall near the mean on performance. In addition, items Q17, Q20, Q22 and Q23 are located within the shared 'satiated desires' area of the grid. So, US bankers might consider resisting allocating additional resources toward these service delivery endeavours at this time.

Items Q16 (provide special ATM services for the disabled), Q18 (have a user-friendly system to make ATM transactions easier) and Q19 (connect me immediately to the service, with no waiting time) all fall into the 'concentrate here' quadrant. Interestingly, each service item appears to be at or near the mean level of performance in an area deemed relatively important. As a result, while bank managers may consider overall performance in these service areas to be adequate, they might also need to investigate how their performance in these three areas stacks up against that of the competition.

In summary, based on the findings from this sample, US bank managers appear to be offering adequate levels of service performance in the areas that customers value highly and do not appear to be concentrating in areas of technology that customers may not view as particularly valuable. However, the survey data indicate that perhaps several market opportunities are still available.

\section{UK bank patron perceptions}

\subsection{Constructing importance-performance grids}

Table 2 summarises the aggregate views of British bank customers. The 'P-I' column in Table 2 indicates that UK customers tend to evaluate their bank's performance of services at a significantly lower level than the corresponding degree of importance they ascribe to 
each service. Only one service item - Q23 (provide customer-friendly environment whilst waiting in the queue - e.g. present information about services the bank provides) - appears to receive a customer evaluation of bank performance that is greater than the corresponding patron evaluation of the importance of the service. So, it appears that a substantial gap exists between customer perceptions of UK bank performance versus the relative desired performance for selected important service attributes. Additional strategic insights can be visualised by plotting the respective importance-performance means on an I-P grid. The first 13 service items in the table (Q1-Q13) are placed on the grid shown in Figure 4. The final ten service items (Q14-Q23) are plotted in Figure 5. The location of the cross-hairs of the grids in Figures 3 and 4 correspond to the aggregate mean evaluation of service performance (3.64) as well as the mean importance (4.10) ascribed to all 23 service items by the entire sample of UK bank patrons.

\subsection{Overall evaluation of service delivery technologies}

Figure 4 indicates that the sample group of UK banking customers in aggregate offer 'above average' performance evaluations (i.e. greater than 3.64) of bank service delivery technologies in general. Service attributes which appear to be most important to UK customers include items Q1 (be easy to use), Q2 (have convenient hours of operation - 24 hours a day - 7 days a week), Q4 (process my transactions efficiently - so I don't need to wait), Q7 (be capable of performing all transactions accurately) and Q9 (provide accurate records of all transactions that have taken place). While patrons rate bank performance of these services above the aggregate mean, notice that there is still a gap between the perceived level of performance versus the perceived importance of the service. In other words, no service items are plotted in the 'satiated desires' area of the importance-performance grid. Therefore, strategic market opportunities appear to exist for banks that would allocate additional attention and resources toward performing selected important services even better than their competitors.

Three service items (Q5, Q10, and Q11) fell into the 'low priority' quadrant. Item Q5 (provide brochures to new users to explain how to use services) and item Q11 (provide special services for the elderly/disabled-electronic) are only slightly below the mean for both performance and importance. So, Q5 and Q11 may still be considered somewhat important by UK bank patrons. On the other hand, patrons appear to consider item Q10 (be personalised - greet me by using my name) to be a relatively unimportant service delivery attribute. Still, UK banks might want to consider endeavouring to perform somewhat better on these service items in order to close the gap that exists between patrons' perceptions of bank performance versus the relative importance of each service.

\subsection{Perceptions of ATM/telephone/internet banking services}

Figure 5 shows that UK bank patrons appear to offer relatively higher evaluations (i.e. greater than the 3.64 overall mean performance rating) of their bank's delivery of some ATM services. For example, service items Q14 (have ATMs conveniently located), Q15 (provide secure services - well lit, safe, night time ATM banking) and Q18 (have a user-friendly system to make ATM transactions easier) are all located in the 'keep up the good work' quadrant. Two other ATM service delivery attributes - Q16 (provide special ATM services for the disabled) and Q17 (acknowledge me by name on the screen during the transaction) - are plotted in the 'low priority' quadrant which indicates these items 
are considered less important by UK bank patrons. Notice that service item Q17 is plotted off the grid on the far bottom-left of Figure 5. This indicates that customers perceive banks to have very poor performance on a relatively unimportant service attribute. Obviously, bank managers would probably not wish to invest additional attention and resources toward delivering the 'acknowledge me by name on the ATM screen' service attribute.

The remaining items plotted in Figure 5 pertain to telephone and internet banking service delivery technologies. UK customers appear to have a relatively high rating of their bank's performance of what they consider to be a relatively unimportant service item Q23 (provide customer-friendly environment whilst waiting in the queue - e.g. present information about services the bank provides). So, bank managers might consider present resource allocations toward these endeavours to be more than adequate. Another service item which is below the mean for perceived importance is Q22 (provide customer-friendly environment whilst waiting in the queue - e.g. provide music). However, it appears that patrons might still like banks to do somewhat better in performing this service attribute.

The most strategic service item appears to be Q19 (connect me immediately to the service with no waiting time) which fell within the 'concentrate here' quadrant. Since UK patrons rate their bank's performance of this relatively important service attribute to be below the mean, bank managers probably need to allocate increased attention toward reducing the time that patrons spend in the service queue. Two other service items - Q20 (provide voice/online directions for new users) and Q21(provide special communications options-e.g. for sight impaired, hearing impaired, elderly or non-English speaking customers) - that are considered by UK bank patrons to be of average importance may also require additional attention by bank managers.

\section{Comparing US and UK perceptions}

Table 3 indicates that UK customers' perceptions of the performance of their bank service delivery technologies tend to be lower than their US counterparts. However, Table 4 further indicates that British customers may be somewhat less concerned about these same service issues. Specifically, the UK bank patrons in aggregate offered lower ratings for both perceived bank service performance levels (3.64 UK vs. 4.26 US) and the perceived importance (4.10 UK vs. 4.37 US) of the bank services. While the data imply that the UK customers may consider the 23 service attributes detailed in this study to be relatively less important and to be delivered more poorly by their banks, it is also possible that the UK survey subjects overall may simply be more hesitant to give a ' 5 ' rating on a Likert scale of 1 to 5. If the latter is true, then the I-P grids shown in Figures 2 to 5 provide additional analytical value. For example, since the respective mean responses of the independent samples of US and UK customers were used to denote the quadrants of the I-P grids shown in Figures 2 to 5, the figures can promote a direct comparison between the service attributes that each sample group considers to be relatively 'above average' or 'below average' in importance and/or performance.

Figures 2 and 4 illustrate US and UK customer perceptions of bank service delivery technologies overall. A visual comparison of the two figures indicates that both sample groups consider items Q10 (be personalised-i.e. 'greet me by using my name') and Q11 (provide special services for the elderly/disabled-electronic) to be a relatively less important service attribute. However, notice that US bank patrons perceive their banks to be performing a much better job of greeting them by name (i.e. the Q10 item is plotted 
in the 'satiated desires' quadrant in Figure 2) than do their UK counterparts (i.e. Q10 is plotted relatively farther away from the 'satiated desires' area in Figure 4). Both US and UK samples indicate that bank managers may wish to improve upon their current delivery of service attribute Q5 (provide brochures to new users to explain how to use services) which patrons in both countries currently consider to be of mid-importance. Most of the remaining patron evaluations of service delivery technologies overall appear to fall within the 'keep up the good work' quadrant. However, notice that the UK evaluations of performance generally are located on the grid farther to the left of the 'satiated desires' diagonal than the US evaluations of these same services. This indicates that US patrons appear somewhat more satisfied than UK customers regarding the performance of their respective banks on many important service items. Therefore, perhaps a greater opportunity exists for UK bank managers to achieve a competitive advantage by offering relatively exemplary performance on selected services considered most important by their customers - particularly regarding service items Q1, Q2, Q4, Q7, Q9 and Q12.

Figures 3 and 5 illustrate a disparity between US and UK customer perceptions of specific service delivery technologies including ATMs, telephone banking and internet banking. Notice that the grid-plots of UK customer perceptions in Figure 5 indicate that almost every service attribute is relatively far to the left from the 'satiated desires' diagonal. This implies that UK customers are relatively dissatisfied with the current performance of their banks on many service delivery attributes. UK patrons perceive their banks to be performing adequately only on the relatively less important service item Q23 (provide a customer-friendly environment whilst waiting in the queue - e.g. present information about services the bank provides). On the other hand, since the majority of point-plots in Figure 3 are located at or near the 'satiated desires' diagonal, it appears that US bank patrons are more satisfied than their UK counterparts with the performance of their ATMs, telephone and internet banking services. Both sample groups place ATM service items Q14 (have ATMs conveniently located), Q15 (provide secure services - well lit, safe, night time ATM banking), and Q18 (have a user-friendly system to make ATM transactions easier) either at or near the 'keep up the good work' category. However, UK patrons appear less satisfied with their banks' delivery of ATM service attribute Q16 (provide special ATM services for the disabled) and the relatively unimportant service Q17 (acknowledge me by name on the screen during the transaction). In addition, UK patrons appear somewhat less satisfied than US customers with the delivery of telephone and internet banking service attributes Q19 (connect me immediately to the service with no waiting time), Q20 (provide voice/online directions for new users) and Q21 (provide special communications options - e.g. for sight impaired, hearing impaired, elderly or non-English speaking customers). So, perhaps greater strategic opportunities exist for UK bank managers that would endeavour to deliver these services better than competitors.

\section{Conclusion}

While it is certainly desirable for an organisation to seek superior customer evaluations simultaneously across many service delivery fronts, firms often are forced to focus scarce resources toward achieving high performance in selected service areas that their customers consider to be of the highest importance. This research inquiry provides practical insights to bank strategists contemplating whether to invest additional organisational resources toward service delivery technologies such as ATMs, telephone banking and internet banking. 
Essential 'must-have' service delivery technologies should be addressed first before investing in service areas that customers view as 'nice-to-have.' However, it is often difficult to make a clear distinction between service dimensions that customers consider essential versus non-essential. This report outlines 23 attributes of bank service delivery technologies that US and UK bank customers consider most salient in typical bank transactions.

Strategists would also be interested in knowing what their current and prospective customers would consider excellent, sub-standard or 'good enough' performance on key service delivery dimensions. This article describes how I-P grids provide graphical visualisations of customer evaluations of how well banks are performing on important service delivery factors. The grids can serve as heuristic tools that would inform strategic decisions to allocate organisational attentions toward SDTs that customers consider important, yet under-addressed. Another contribution is applying the IPA methodology to a cross-nation inquiry to demonstrate how I-P grids offer an effective and parsimonious approach toward quickly visualising and comparing US and UK bank patron perceptions of SDTs.

This study has limitations which do not influence the integrity of the findings presented in this report, but which do place certain boundaries upon the conclusions that can be drawn from the findings. Opportunities for future research are suggested. For example, since mall-intercept convenience samples were utilised in this report, the findings presented here cannot be considered statistically representative of the overall US and UK populations. Future research enquiries might wish to employ nationally-representative sampling plans. The present study may also not be generalisable to other national, cultural or socio-economic contexts. Researchers could examine the perceptions of bank patrons residing in other nations or in different economic circumstances. Additional inquiries could explore differences between various consumer cohort groups (e.g. employing demographic and psychographic variables) regarding their respective performance expectations for selected dimensions of bank SDTs.

Organisational strategists are cautioned to avoid an over-confident, long-term adherence to the strategic inferences suggested by the subjective plotting of the grid cross-hairs that delineate 'less important' and 'low performance' service dimensions. In an ever-changing, competitive global market place, some banks will pursue continuous innovations in service delivery technologies. So, current customer delight with a particular service dimension can rapidly dissolve into baseline expectations of service. Bank strategists can remain vigilant to changing competitive positioning by employing multiple iterations of I-P grid analysis to assess customer perceptions and expectations across time and location. In addition, customers often possess a minimum threshold of acceptability regarding selected service delivery processes. If bank performance on a selected service slips below a customer's acceptability threshold, that customer may exit the banking relationship. So, the subjective placement and interpretation of the I-P grid cross-hairs which denote 'less important' or 'low performance' service dimensions is obviously a rather delicate and vital activity that would be best served by an analyst with extensive industry insight.

Still, the strength of the I-P grid is that it offers a practical, parsimonious approach toward aggregating customer perceptions into an heuristic, graphical display which suggests corresponding actionable strategies toward allocating scarce organisational resources. The present study shows how the IPA methodology is useful to academics and practitioners seeking an understanding of bank customer perceptions of service delivery 
technologies. The 23 dimensions of service delivery detailed in this report capture many of the technology-based service attributes that US and UK bank customers currently find important. So, this report offers a strong foundation to inform future endeavours to capture additional dimensions of customers' ever-changing desires and expectations for service performance, and then quickly adapt bank service delivery technology offerings to meet those changing desires.

\section{References}

Albro, W. (1999) 'A strategy grid helps improve customer service', Bank Marketing, Vol. 31, No. 12 (December), p.36

Alstad, J. (2002) 'Use your service edge to your online advantage', American Banker, Vol. 167, No. 46, pp.1-3.

Bateson, J. (1985) 'Perceived control and the service encounter', in The Service Encounter; Managing Employees/Customer Interaction in Service Businesses, J.A. Czepiel, C.A. Suprenant and M.R. Solomon, (Eds.), Lexington MA: Lexington Books.

Byers, R. and Lederer, P. (2001) 'Retail bank service strategy: a model of traditional, electronic, and mixed distribution choices', Journal of Management Information Systems, Vol. 18, No. 2, pp.133-156.

Cowles, D. and Crosby L. (1990) 'Consumer acceptance of interactive media', The Services Industries Journal, Vol. 10, No. 3, pp.521-540.

Dabholkar, P. (1994) 'Technology based service delivery', Advances in Services Marketing and Management, Vol. 3, pp.241-271.

Ennew, C.T., Reed, G.V. and Binks, M.R. (1993) 'Importance-performance analysis and the measurement of service quality', European Journal of Marketing, Vol. 27, No. 2, pp.59-70.

Ford, C., Joseph, M. and Joseph, B. (1999) 'Importance-performance analysis as a strategic tool for service marketers: the case of service-quality perception of business students in New Zealand and the USA', The Journal of Services Marketing, Vol. 13, No. 2, pp.167-177.

Hawes, J.M. and Rao, C.P. (1985) 'Using importance-performance analysis to develop health care marketing strategies', Journal of Health Care Marketing, Vol. 5, No. 4 (Fall), pp.19-25.

Hermmasi, M., Strong, K. and Taylor, S. (1994) 'Measuring service quality for planning and analysis in service firms', Journal of Applied Business Research, Vol. 10, No. 4, pp.24-34.

Joseph, M. and Stone, G. (2003) 'An empirical evaluation of US bank customer perceptions of the impact of technology on service delivery in the banking sector', International Journal of Retail and Distribution Management, Vol. 31, No. 4, pp.190-202.

Joseph, M., McClure, C. and Joseph, B. (1999) 'Service quality in the banking sector: the impact of technology on service quality', International Journal of Bank Marketing, Vol. 17, No. 4, pp.182-191.

Kohli, A.K. and Jaworski, B.J. (1990) 'Market orientation: the construct, research propositions, and managerial implications', Journal of Marketing, Vol. 54, April, pp.1-18.

Ledingham, J. (1984) 'Are consumers ready for the information age?', Journal of Advertising Research, Vol. 24, No. 4, pp.31-37.

Martilla, J.A. and James, J.C. (1977) 'Importance-performance analysis', Journal of Marketing, Vol. 41, January, pp.77-79.

Motley, L.B. (1999) 'Customer surveys that work’, Bank Marketing, Vol. 31, No. 12 (December), p.40.

Narver, J.C. and Slater, S.F. (1990) 'The effect of a market orientation on business profitability', Journal of Marketing, Vol. 54, October, pp.20-35. 
Ortinau, D., Bush, A., Bush, R. and Twible, J. (1989) 'The use of importance-performance analysis for improving the quality of marketing education: interpreting faculty-course evaluations', Journal of Marketing Education, Summer, pp.78-86.

Pyun, C., Scaggs, L. and Nam, K. (2002) 'Internet banking in the US, Japan and Europe', Multinational Business Review, Fall, pp.73-81.

Quinn, B. (1996) 'The productivity paradox is false: information technology improves service performance', Advances in Services Marketing and Management, Vol. 5, pp.16-21.

Rust, R. and Zahorik, A. (1993) 'Customer satisfaction, customer retention and market share', Journal of Retailing, Vol. 69, Summer, pp.267-283.

Slater, S.F. and Narver, J.C. (2000) 'Intelligence generation and superior customer value', Journal of the Academy of Marketing Science, Vol. 28, (Winter): pp.120-127.

Swinyard, W.R. (1980) 'Strategy development with importance/performance analysis', Journal of Bank Research, Vol. 10, No. 4, pp.228-234. 